\title{
Observations of resonant scattering in the thermosphere and upper mesosphere in the winter season of 2021
}

\author{
Vasily Bychkov ${ }^{1, *}$, Ilia Seredkin ${ }^{1}$, Alexei Dmitriev ${ }^{2,3}$ \\ ${ }^{1}$ Institute of Cosmophysical Research and Radio Wave Propagation FEB RAS, p. Partunka \\ Kamchatka Territory, st. Mirnaya 7 \\ ${ }^{2}$ National Central University, Chongli 320, Taiwan \\ ${ }^{3}$ Moscow State University, Moscow, Russia
}

\begin{abstract}
An analysis of the Kamchatka lidar station data obtained in January-February 2021 is presented. Pronounced light scattering layers at altitudes of $300 \mathrm{~km}$ have been detected. Layers at these heights appear during precipitation of electrons with energies of about $300 \mathrm{eV}$. Analysis of the lidar data showed that increased light scattering was observed at the heights of the mesosphere, accompanied by an increase in the ionospheric parameter fmin. It was concluded that the observed aerosol formations in the mesopause region could be caused by precipitation of charged particles with energies of $\sim 500 \mathrm{keV}$. Aerosol formations in the area of $60-75 \mathrm{~km}$ should be recognized as imaginary. This is a manifestation of resonant scattering by excited ions of atomic nitrogen
\end{abstract}

\section{Introduction}

Lidar station Kamchatka was put into operation in autumn 2007. In March 2008, resonance scattering by excited ions of atomic nitrogen at a wavelength of $532 \mathrm{~nm}$ was detected. Backscattering signals at a wavelength of $532 \mathrm{~nm}$ at altitudes of 100-300 km are presented in [1]. In [2-3], the results of two-frequency sounding in the area of $25-500 \mathrm{~km}$ are presented. In 2021, lidar sounding of the atmosphere was carried out at a wavelength of 532 $\mathrm{nm}$ on two receiving channels in the range of $10-600 \mathrm{~km}$.

\footnotetext{
*Corresponding author: vasily.v.bychkov@gmail.com
} 


\section{Equipment and measurement methods}

Recording of reflected signals was carried out on two receiving channels - for the main (25$600 \mathrm{~km})$ and reflected $(10-600 \mathrm{~km})$ signals. Several percent of the main signal was separated by a glass plate installed in the fiber at an angle of 45 degrees to the light flux and directed to another photomultiplier [5]. A continuous signal profile in the range of $10-600$ $\mathrm{km}$ was obtained by stitching the profiles of the main and reflected signals. Figure 1 shows the working scheme of the lidar.

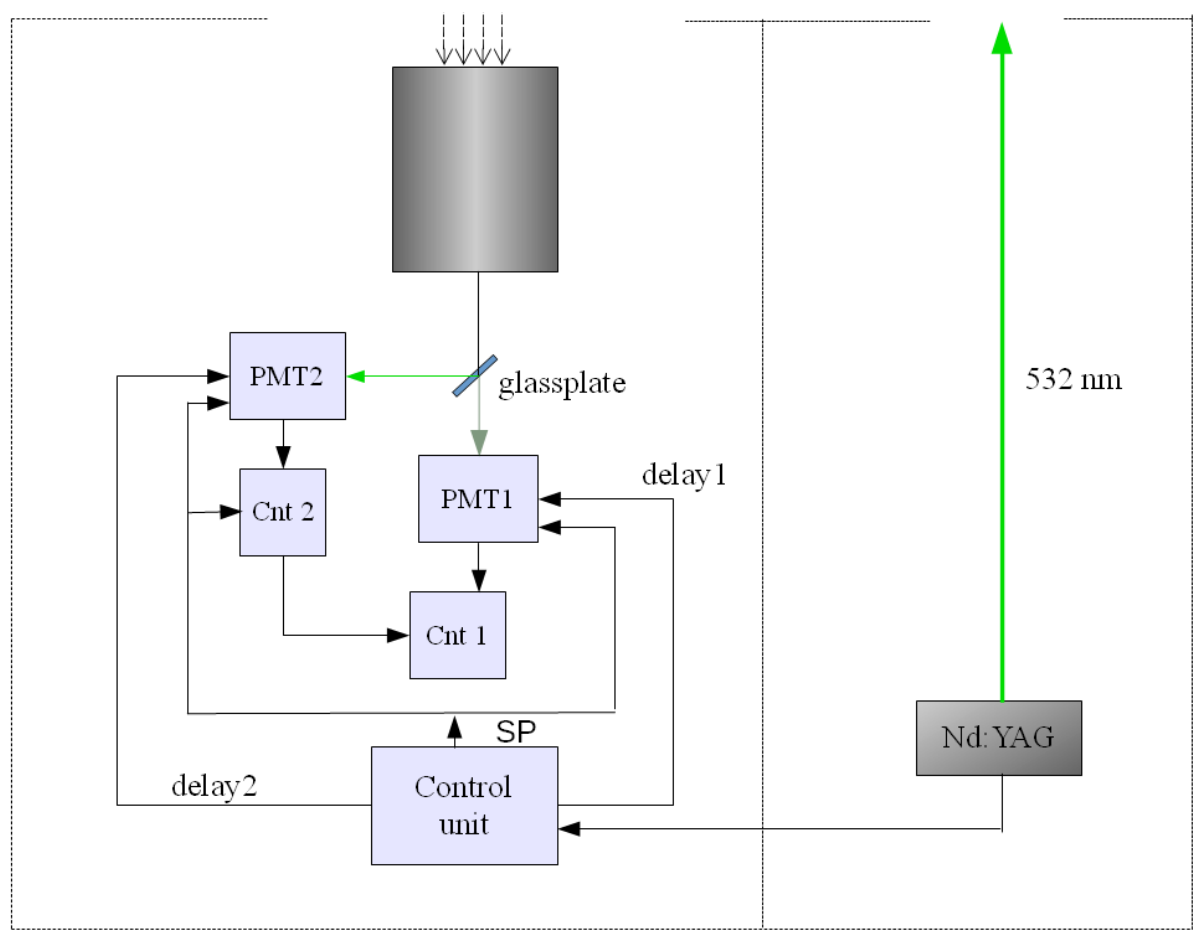

Fig. 1. Lidar scheme: SP - sync pulse generated by laser, Cnt - photon counter. PMT - pnotomuıiplier tube, delay - blocking pulse duration $\mu$ s, set in the control unit.

The aim of the research was to observe the appearance of precipitation of superthermal electrons into the thermosphere and the appearance of aerosol in the middle atmosphere.

The precipitation of superthermal electrons similar to the events of the autumn of 2017 $[4,5]$ was not registered in 2020-21. This is due to the very low geomagnetic activity at the minimum of the solar cycle. During quiet times, the precipitation of energetic electrons from the outer radiation belt practically disappears.

Equipment, as well as methods of measuring and processing signals are given in $[4,5]$. A lidar with a $\mathrm{Nd}$ : YAG laser was used to generate radiation at a wavelength of $\lambda=532.08$ nm. To exclude photomultiplier illumination from near-field signals in both receiving channels, the photomultiplier was electronically locked. A dipole transition was studied for an excited nitrogen ion with a wavelength of $532 \mathrm{~nm}$. (Table 1). 
Table 1. Dipole transition of an excited nitrogen ion in the laser emission band

\begin{tabular}{|c|c|c|c|c|c|c|c|c|}
\hline & Component & Wavelength (nm) & Lower level & Term & J & Top level & Term & J \\
\hline 1 & NII & 532,0958 & $2 \mathrm{~s} 2 \mathrm{p}^{2}\left({ }^{4} \mathrm{P}\right) 3 \mathrm{p}$ & ${ }^{5} \mathrm{P}^{\circ}$ & 1 & $2 \mathrm{~s} 2 \mathrm{p}^{2}\left({ }^{4} \mathrm{P}\right) 3 \mathrm{~d}$ & ${ }^{5} \mathrm{P}$ & 2 \\
\hline
\end{tabular}

The state of the ionosphere was monitored according to the results of measurements of the Parus A ionosonde. The computers controlling the operation of the ionosonde and lidar are synchronized by GPS.

\section{Experimental data}

As already noted, precipitation of superthermal electrons into the thermosphere in 2020 was not registered. In January 7, 13 and 27 and in February 5, 12 and 15, mild precipitations appeared. Figure 2 shows the values of the total "signal-background" modified by multiplying by the coefficient $\mathrm{k}=(\mathrm{H} / 100)^{2}$, where $\mathrm{H}$ is the height in $\mathrm{km}$ [4].
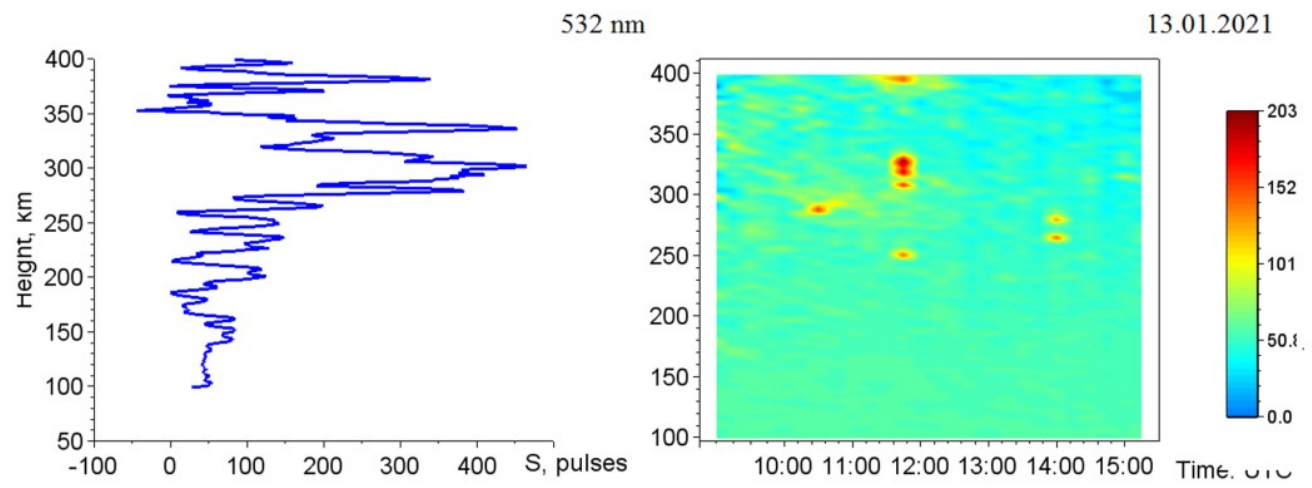

Fig. 2. Lidar "signal-background" plotted according to data from January 13, 2021.

Figure 3 shows the results of atmospheric sounding by the Parus-A ionosonde. (3a), the profile of the scattering ratio for the first 2.5 hours of observations ( $3 b)$ and the total overnight profile (3c). Attention is drawn to the behavior of the ionospheric parameters fmin and foEs. The time intervals for the accumulation of lidar signals were chosen taking into account the fact that at the beginning of observations the fmin values were close totheir usual values of about 1 . 

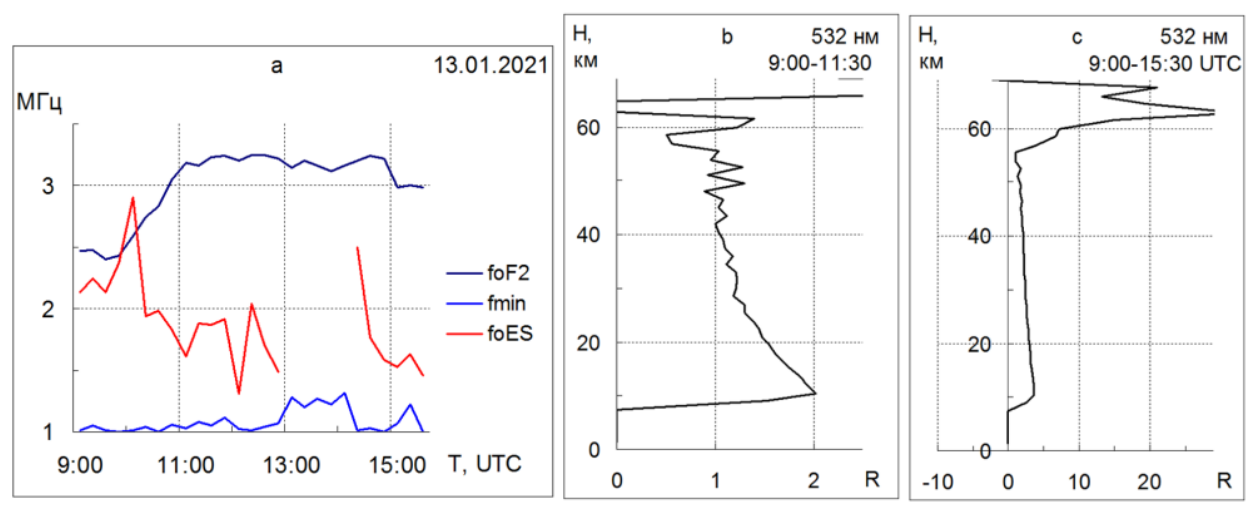

Fig. 3. Values of $\mathrm{foF}_{2}$, fmin, foEs ( a ) and profiles of the scattering ratio at the beginning of the sounding session ( $b$ ) and total over the night of 01/13/2021 (c).

The geomagnetic situation during measurements in January is represented by the Dst index in Figure 4. It can be seen that the observation intervals on January 7, 13, and 27, 2021 , fall on the recovery phase of recurrent magnetic storms. It is known that during these periods the electrons of the outer radiation belt are actively accelerated to energies of hundreds of $\mathrm{keV}-\mathrm{MeV}$ and, and can precipitate into the atmosphere at high and middle latitudes, causing additional ionization of the upper and middle atmosphere [6].

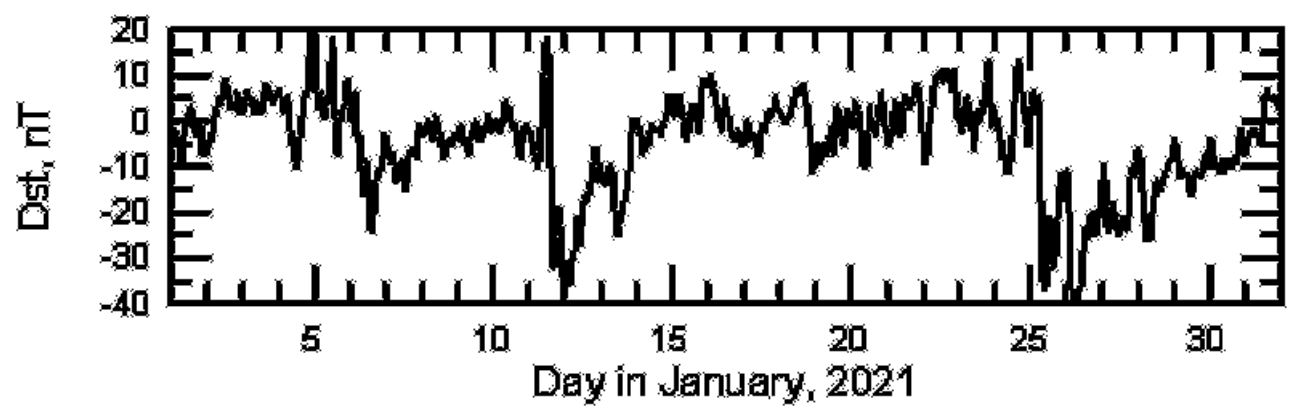

Fig. 4. Dynamics of the geomagnetic activity index Dst in January 2021 Small negative variations are associated with recurrent magnetic storms.

\section{The discussion of the results}

An increase in the nighttime values of fmin means an increase in the concentration of free electrons in the upper mesosphere. At night, this is caused by precipitation of electrons with energies of hundreds of $\mathrm{keV}$. As noted in [5], the maximum of the scattering ratio $\mathrm{R}$ is located above the maximum of ionization produced by precipitating electrons.

The profiles of lidar signals in the range of 50-110 km for the same accumulation intervals as in Fig. 3 were compared with the ionization rate profile for a monoenergetic electron flux constructed according to the method described in [7]. It is shown that the height of the maximum of the ionization rate coincides with the height of the maximum of the signal for an electron flux with an energy of $500 \mathrm{keV}$. 
Thus, we can conclude that on January 13, 2021, near 12:00 UTC, precipitations of electrons with energies of 300-330 eV were observed, according to the results of [4], and in the interval 13: 00-15: 30 UTC with energies of about $500 \mathrm{keV}$.

The Es layer was in the area of 100-110 km. Its disappearance at the moments of anomalous growth of fmin can give rise to the assumption that the layer is corpuscular, and its disappearance is associated with an increase in the energy of precipitating electrons. This is not true. The absence of a resonant scattering signal in the range of 100-110 km indicates that the layer is correctly defined by experts as type $\mathrm{f}$ - flat.

Analysis of ionograms showed that the absence of foEs values, which coincides in time with an increase in fmin, can be associated with a large absorption of radiowave. It means the absence of a sufficient return signal, but not real Es disappearance. Large fmin values, close to foEs values, lead to the fact that weakly pronounced fragments of the Es track are reflected in ionograms at an altitude of $100 \mathrm{~km}$, which do not allow determining the exact value of foEs.

The estimates of the energies of the precipitated electrons obtained from the lidar data are confirmed by the results of satellite measurements. Figure 5 shows the data of measurements of electron fluxes and energies on the Metop 1 meteorological satellite. It flew both east and west of Kamchatka during lidar observations.
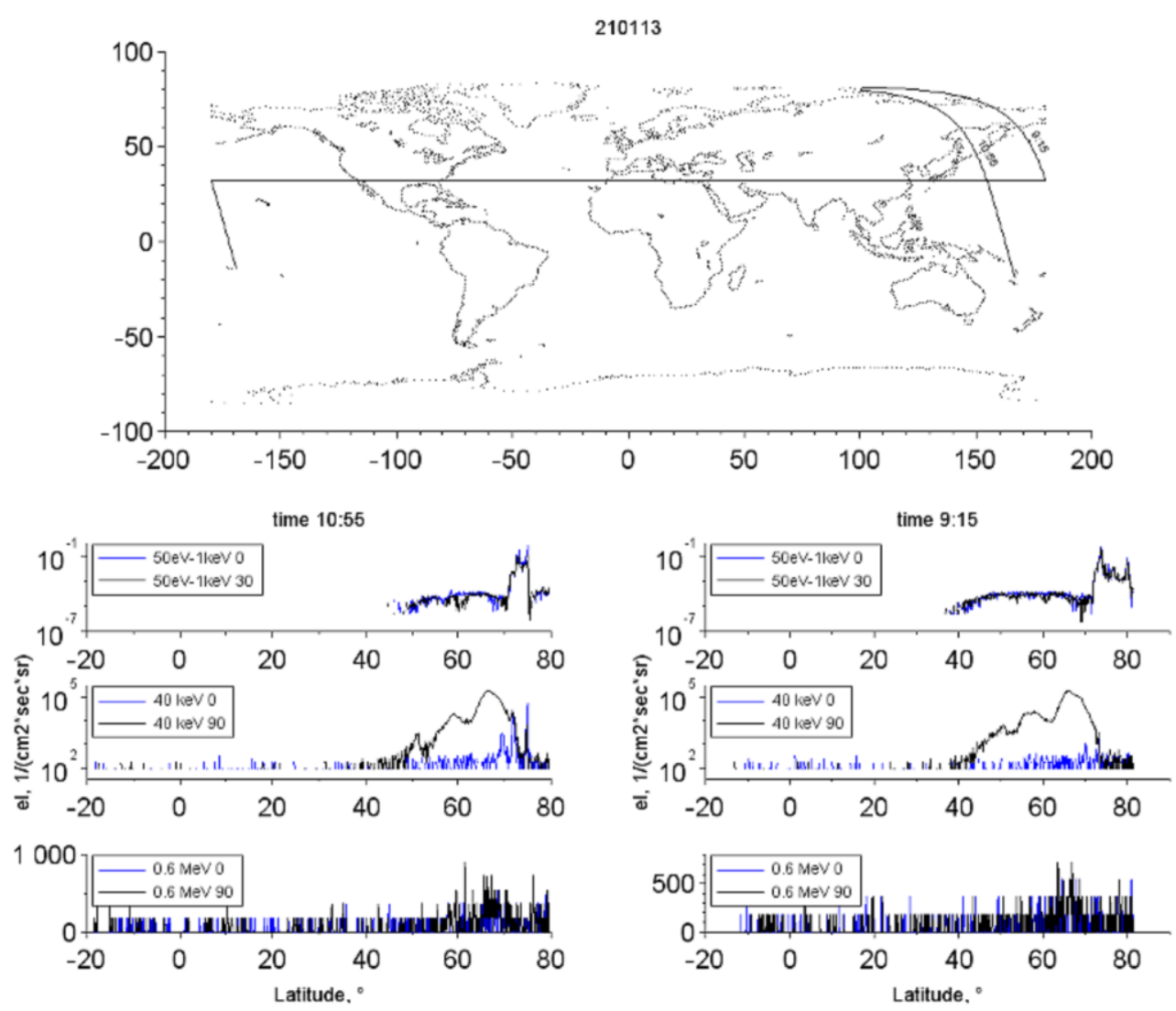

Fig.5. Electron fluxes recorded on the Metop 1 satellite during lidar observations on January 13, 2021. 
The energy of $500 \mathrm{keV}$, determined from the lidar data, fits well into the energy range 40-600 keV, shown in the middle panel of Fig. 5. Very low values of superthermal electron fluxes also do not contradict the lidar data, since both satellite passages occurred before the appearance of the layer at an altitude of $300 \mathrm{~km}$. Verification of satellite data for other days with Dst index values close to zero showed the absence of fluxes of both superthermal electrons and with energies in the range of $40-600 \mathrm{keV}$.

We also present the data of studies of the aerosol distribution in the middle atmosphere of Kamchatka, presented in [8], in which the presence of "non-aerosol" scattering in the lidar data is discussed. Figure 6 present data showing the correlation of the ionospheric parameter fmin with the scattering ratio $\mathrm{R}$, total over 5-6 $\mathrm{km}$ layers in the mesopause region.

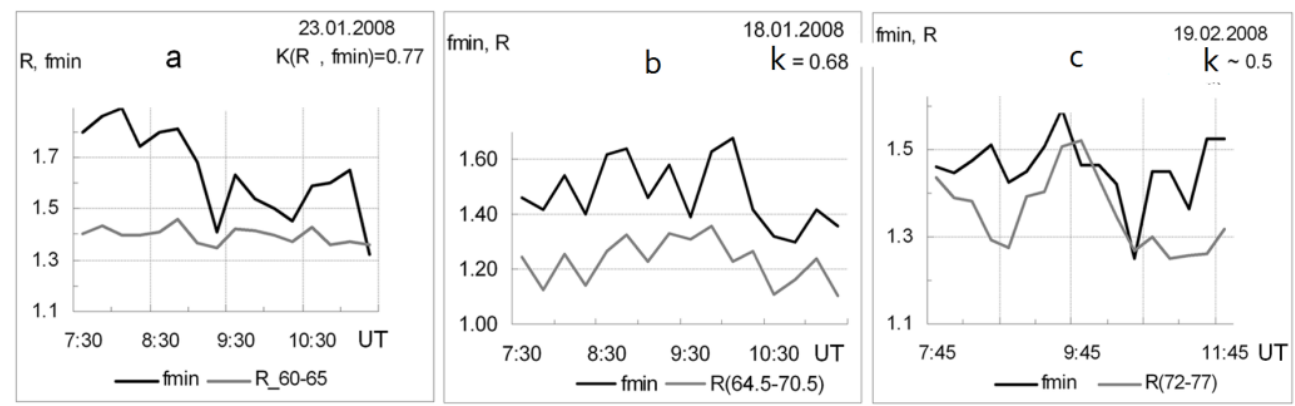

Fig. 6. Correlation of the ionospheric parameter fmin with the scattering ratio $\mathrm{R}$ in the mesosphere

It was shown in [8] that at the lowest temperatures observed from 2007 to 2011, the content of water vapor in the mesosphere was not enough by more than an order of magnitude for their condensation with aerosol formation. In this case, aerosol layers in the mesosphere were observed.

The abrupt termination of the correlation at the end of observations on February 19 (Fig.6c) means that the phenomenon is controlled by a fast-flowing process. The correlation of the signal with fmin suggests that this process is the precipitation of electrons. Comparisons with the results of measurements from the Demeter satellite showed that precipitations of relativistic electrons were observed and these electrons could ionize in the region of $65-80 \mathrm{~km}$.

The data presented in 2008 show that the precipitations of electrons into the mesosphere observed in January-February 2021 are not unique events and can occur, for example, during the restoration of the magnetosphere after geomagnetic disturbances.

\section{Conclusions}

Imaginary aerosol formations in the mesosphere when probed at a wavelength of 532.08 $\mathrm{nm}$ is an expected and ordinary event. The reason is resonance scattering by excited ions of atomic nitrogen, which are formed during the ionization of the atmosphere. 


\section{Funding}

The work was carried out within the state assignment on the theme (2021-2023) Physical Processes in the System of Near Space and Geospheres under Solar and Lithospheric Impacts. Registration no. AAAA-A21-121011290003-0 with the use of equipment of the Collective Use Center of the Institute of Cosmophysical Research and Radio Wave Propagation, Far Eastern Branch, Russian Academy of Sciences, North-Eastern Heliogeophysical Center (SKR_558279, UNU 351757). The work was partly financially supported by the Russian Foundation for Basic Research (grant nos. 19-05-00543 A and 19-5-700008 r_a).

\section{References}

1. V.V. Bychkov, Y.A.Nepomnyashchiy, A.S. Perezhogin, B.M. Shevtsov, Earth, Planets and Space (2014)

2. V.V. Bychkov, Y.A.Nepomnyashchiy, A.S. Perezhogin, B.M. Shevtsov, Atmospheric and Oceanic Optics, 28 (2015)

3. V.V. Bychkov, A.S. Perezhogin, I. N. Seredkin, B.M. Shevtsov, SPIE. Proc., 10466 (2017)

4. V. V. Bychkov, I. N. Seredkin, Atmospheric and Oceanic Optics, 34 (2021)

5. V. V. Bychkov, I. N. Seredkin, V. N. Marichev, Atmospheric and Oceanic Optics, 34 (2021)

6. A.V. Dmitriev, J.-K. Chao, J. Geophys. Res., 108 (2003)

7. M.G. Deminov, Earth's Ionosphere, in Plasmennaya geliogeofizika (Plasma Heliogeophysics), Fizmatlit, 2 (2008)

8. V.V. Bychkov, A.S. Perezhogin, A.S. Perezhogin, B.M. Shevtsov, V.N. Marichev, G.G. Matvienko, A.S. Belov, A.A. Cheremisin, Atmospheric and Oceanic Optics, 25 (2012) 